\title{
LA INTERPRETACIÓN DEL ACTO TESTAMENTARIO
}

\author{
FERnando Vidal RamíREZ*
}

Resumen:

Al constituir el acto testamentario la manifestación de voluntad del testador por medio del cual dispone, total o parcialmente, sus bienes para después de su muerte, ordenando su propia sucesión dentro de los límites y con las formalidades de ley; supone la interpretación de dicho acto un recurso por medio del cual se tiende a desentrañar la genuina determinación del sentido y alcance de la voluntad de testar, recurriendo para ello a las reglas generales de interpretación contenidas en el libro segundo del Código Civil, dedicado al acto jurídico; las cuales son desarrolladas por el autor en las líneas siguientes.

Palabras clave: sucesión - testamento - testador - interpretación.

A bstract:

The testamentary act is the manifestation of will of the testator by which he arranges his assets in a total o partial way for after his death. Therefore, the interpretation of this act is a resource to establish the sense to the will of the testator, resorting to the general rules of interpretation of the second book of the Civil Code dedicated to the juridical activity, which are developed by the author in the following lines.

Key words: succession - testament - testador - interpretation

\section{Sumario:}

1. El Acto Testamentario. 2. El contenido del acto testamentario. 3. Las formalidades del acto testamentario. 4. La interpretación.

Miembro del Consejo Consultivo del Poder Judicial Peruano. 


\section{EL ACTO TESTAMENTARIO}

El acto testamentario es un manifestación de voluntad y, por ella, un genuino acto jurídico que se forma con la sola voluntad del testador. Es un acto personal ísimo, pues sólo puedeser cel ebrado por un testador y las disposiciones en él contenidas deben ser la expresión directa de su voluntad, pues así lo establece preceptivamenteel art. $690^{\circ}$ del Código Civil.

La finalidad del acto testamentario, como genuino acto mortis causa, es la disposición de sus bienes por el testador, total o parcial mente, para después de su muerte, ordenando su propia sucesión dentro de los límites de la ley y con las formalidades que ésta señala, como lo puntualiza el art. 6860 del Código Civil. Es por tanto, si bien es un acto unilateral estambién un acto recepticio, en cuanto su voluntad expresada en el testamento va dirigida a quienes están Ilamad os por la ley a sucederlo y a quienes les está otorgando legados u otras liberal idades y derechos.

Si bien los hijos del testador y demás descendientes, los padres y los demás ascendientes, y el cónyuge, son herederos forzosos y están vinculados a él por una relación jurídica determinada por el parentesco, puede darse el caso que al guno de estos parientes pueda ser desheredadoy, aunquela relación jurídica por razón deparentesco subsista, la relación sucesoria queda afectada y puede llegar a extinguirse. Además, puede el testador crear una relación sucesoria mediantela institución deherederos voluntarios y de legatarios.

El anteriormente acotado art. 6860 establece también que son válidas las cláusulas testamentarias de carácter no patrimonial.

El acto testamentario debe ser cel ebrado documentariamentey observándose las formalidades establecidas por el Código Civil, por lo que atendiendo a la complejidad desu contenido, la interpretación del testamento reviste especial importancia.

\section{EL CONTENIDO DEL ACTO TESTAMENTARIO}

El acto testamentario es un acto jurídico de disposición de bienes y de disposiciones no patrimoniales que quedan contenidas en ese documento que se denomina testamento. Como ya lo hemos advertido, el art. 6860 del Código Civil le da la mayor amplitud a las disposiciones testamentarias, las que pueden 
tener o no carácter patrimonial. Por ello, es conveniente acotar que las disposiciones testamentarias, aún cuando se nutren del postulado de la autonomía de la voluntad, deben enmarcarse en conformidad con la normativa legal, que contiene normas imperativas, por lo que en caso de colisión van a tener prevalencia sobre las disposiciones del testador.

Puedeser materia contenida en el testamento el ordenamiento por el testador de su propia sucesión. La porción de la legítima la puede distribuir entre sus herederosforzososy si hubiera hecho un anticipo en favor de alguno deelloso de varios, puede disponer la dispensa de la colación y, a falta de herederos forzosos, puede instituir herederos voluntarios, y a sus sustitutos, y distribuir entre ellos la porción de la legítima. La distribución de la porción de libre disposición puede también ordenarla e instituir legatarios, y a sus sustitutos, señal ando los bienes que les asigna.

Puedeel testador constituir una fundación señal ando su finalidad y los bienes que afecta, designando a sus administradores, o instituir un cargo en un legado y, además, entreotros actos de disposición, constituir un derecho desuperficie.

Puedeser también materia contenida en el testamento la privación departicipar en la porción de la legítima a un heredero forzoso mediante desheredación y revocarla, así como otorgar perdón al indigno de sucederlo.

El testador puede también reconocer y condonar obligaciones. Con sus disposiciones de carácter no patrimonial puede el testador reconocer a un hijo extramatrimonial, creando, de esta manera, la relación jurídica paterno-filial y la consecuente relación sucesoria.

Para el cumplimiento de sus disposiciones puede el testador nombrar uno o mas al baceas o ejecutores testamentarios y, si nombra a varios, señalarles su modo de actuación y sus remuneraciones.

Puedeel testador, por último, revocar un testamento anterior, total o parcial mente, mediante un testamento posterior que de contenido a una diferente y última voluntad testamentaria.

\section{LAS FORM ALIDADES DEL ACTO TESTAMENTARIO}

El Código Civil distinguelos actos testamentarios en ordinarios y en especiales. 
Según el art. 691, los testamentos ordinarios son el otorgado por escritura pública, el cerrado y el ológrafo, mientrasquelos testamentos especiales son los permitidos según las circunstancias previstas por el mismo Código, quereconoce el testamento militar y el testamento marítimo.

A tendiendo a la trascendencia del contenido del acto testamentario, el Código Civil le prescribe obligatoriamente la forma escrita y lo reviste de formalidades cuyainobservancia determina su nulidad, pues setrata deforma y formalidades ad solemnitatem, distinguiendo, en su art. 695o, las formal idades comunes, que vienen a ser, además de la forma escrita, la indicación dela fecha deotorgamiento del testamento y la firma del testador, advirtiendo que las formalidades específicas de una clase de testamento no pueden ser aplicadas a los de otra.

Adicionalmentey siendo el acto testamentario un acto personalísimo, pues sus disposiciones deben ser expresión directa de la voluntad del testador, los arts. $692^{\circ}$ y 6930, respectivamente, disponen que los analfabetos y los ciegos sólo puedan celebrar el acto testamentario medianteescritura pública, cumpliéndose las formalidades del art. 6970, y que los mudos y los sordomudos, conformeal art. 694\%, sólo pueden otorgar testamento cerrado o testamento ol ógrafo.

El testamento en escritura pública es el querevistela mayor solemnidad. El art. 6960 del Código Civil dispone que deben reunirse en un solo acto, desde el principio hasta el fin, el testador, el notario y los dos testigos testamentarios, queel testador exprese su voluntad dictando su testamento al notario o dándole por escrito las disposiciones que debe contener su testamento, que el notario escriba el testamento de su puño y letra en su registro de escrituras públicas, que cada una de las páginas del testamento sea firmada por el testador, el notario y los testigos testamentarios, queel testamento sea leído por el testador, el notario y uno delos testigos testamentariosy quedurantela lectura, al fin de cada cláusula se verifique, oyendo al testador, si lo contenido en ella es la expresión de su voluntad y que el testamento sea firmado por el testador, el notario y los testigos testamentarios.

El testamento cerrado es el documento que contiene la última voluntad del testador. Según el art. 6999, debe estar firmado en cada una de sus páginas o al final si ha sido manuscrito por el mismo testador, debeser colocado dentro de un sobre debidamente cerrado o deuna cubierta clausurada de manera queno pueda ser extraído sin rotura o alteración de la cubierta y entregado personalmente por el testador a un notario ante dos testigos, manifestándole 
que contiene su testamento. El notario debeextender en la cubierta un acta en la queconstesu entrega por el testador y su recepción por el notario, firmada por el testador, dostestigos y el notario, quien la transcribirá a su registro, firmando la trascripción las mismas personas, todo lo cual debe practicarse en un sólo acto, debiendo el notario entregar una copia certificada del acta al testador.

El testamento ológrafo, según el art. 7070, sólo requiere quesea totalmenteescrito, fechado y firmado por el propio testador.

Por la trascendencia misma del acto testamentario, el Código Civil, los denominados testamentos especiales deben también observar formalidades. Así, para el testamento militar, quees el acto testamentario que pueden otorgar los miembros de las Fuerzas Armadas y de las Fuerzas Policiales, que en tiempo de guerra estén dentro o fuera del país, así como las personas que sirvan a dichas Fuerzas y los prisioneros de guerra, como también los que se encuentren en poder del enemigo, según el art. 713으, se otorga anteun oficial o jefe de destacamento, puesto o comando al que pertenezca el testador, o ante el médico o el capellán que lo asiste. El testamento debe constar por escrito firmado por el testador, por la persona antela cual lo otorgó y por testigos y, si sólo consta por escrito y el testador muere, se considera como testamento ológrafo.

El denominado testamento marítimo debe observar formalidades similares a las del testamento militar, con la diferencia que puedeser otorgado en buques de guerra y también en buques mercantes. Según los arts. 7160 y 717으, el testamento seotorga anteel comandante del buqueo antequien sehaya delegado tal función. El testamento debeconstar por escrito y ser firmado por el testador, la persona ante la cual ha sido otorgado y por testigos, siendo anotado en el diario de bitácora.

Como testamento especial habría que considerar también al denominado testamento aéreo, que el Código Civil no considera, pero que si ha recibido referencias en la doctrina nacional ${ }^{1}$ y está previsto en la Ley de Aeronáutica Civil.

Como puede inferirse, las formalidades prescritas para el acto testamentario tienen por finalidad dotarlo de seguridad jurídica mediante las formalidades dirigidas a la preservación de la voluntad del testador y de los derechos que crea, regula, modifica o extingue, sean o no de naturaleza patrimonial. 


\section{LA INTERPRETACIÓN}

La interpretación del testamento revisteespecial importancia, pues su conteni do es la voluntad del testador, dictada al notario si el testamento es por escritura pública, manuscrito por el testador si es ológrafo o manuscrito o dictado a un tercero si es cerrado, pero en todos los casos debe ser la expresión directa desu voluntad, la que sólo puede darsea conocer, para los efectos sucesora les cuando el testador ha fallecido. La interpretación, entonces, debe ser la genuina determinación del sentido y del al cance de sus disposiciones testamentarias.

El acto testamentario, como la generalidad delos actos jurídicos, genera también una relación entrela voluntad interna del quelo cel ebra y la manifestación con la quela exterioriza. Pero, siendo un acto unilateral, el testamento no tiene otra finalidad quela de dar a conocer la voluntad del testador y, siendo también un acto mortis causa, esa voluntad no lo liga a otro sujeto, ni heredero ni legatario, ni acreedor ni beneficiario de alguna liberalidad dispuesta.

La relación entrela voluntad interna del testador y lo que expresa mediantela manifestación con la cual la exterioriza, ha sido siempre una cuestión que ha concitado el interés dela doctrina y generado criterios contrapuestos. La misma doctrina ha establecido una dualidad, aunque con algunas alternativas, para distinguir los criterios quelos doctrinadores han desarrollado pues, para unos, la voluntad interna debe prevalecer sobre la manifestada y, para otros, la prevalecía debe ser la de la voluntad manifestada sobre la voluntad interna, vale decir, que se ha establecido una contraposición entre los criterios agl utinados como subjetivos o voluntaristas y los aglutinad os como objetivistas, aunque con algunas alternativas eclécticas.

A tendiendo, entonces, a las características del acto testamentario y a su finalidad, así como que no vincula al testador con los beneficiarios de su testamento, la corriente doctrinal para su interpretación se ha orientado hacia la prevalencia dela vol untad interna porque delo quesetrata es llegar a conocer lo queel testador ha querido. Estecriterio voluntarista ha sido acogido demanera explícita por diversos códigos, como esel caso delos códigos chileno (art. 10699), español (art. 675ㅇ) y mexicano (art. 1302ㅇ), por ejemplo.

Pero el Código Civil peruano no ha dado cabida a normas de interpretación relativas al acto testamentario y, en consecuencia, sistemáticamente, le vienen a ser aplicables las normas de interpretación previstas para los actos jurídicos 
en general y que son las que contienen los arts. 168ㅇ, $169^{\circ}$ y $170^{\circ}$ del Código Civil, que son normas que tienen una clara y definida orientación objetivista, esto es, la de hacer prevalecer lo expresado mediante la manifestación sobre la voluntad interna, pero sin negar la correlación que debe existir entreambas, pues debe presumirse que la voluntad interna está contenida en la manifestación y atenuando, además, el rigor objetivista al disponer la aplicación del principio dela buena fe. A demás, antela fal ta de una norma de interpretación relativa al acto testamentario y el carácter imperativo de las normas de interpretación para la generalidad de los actos jurídicos, quien asuma la labor hermenéutica de un testamento no puede obviar ni soslayar la gravitación del criterio adoptado como norma general contenido en el ya acotado art. 168으.

La doctrina nacional no le ha dado mayor atención a la probl emática rel ativa a la interpretación del testamento, con excepción de Guillermo Lohmann ${ }^{3}$.

Al hacer el examen dela aplicabilidad delas reglas generales de interpretación de los actos jurídicos, en relación con el art. 168으, luego de la disquisición del objeto de la interpretación, que para Lohmann es la voluntad normativa exteriorizada, y el cómo interpretar, que para el mismo autor es el marco conceptual al que deben sujetarse los resultados de la tarea interpretativa, concluye en que la interpretación no debe llegar a conclusiones que estén en desacuerdo con lo expresado ${ }^{4}$, con lo que, a mi juicio, coincide con lo que he venido sosteniendo en cuanto que la labor hermenéutica debe focalizar «lo expresado», en estecaso lo expresado por el testador, para la determinación del significado, sentido y al cance de su última voluntad manifestada ${ }^{5}$.

El testamento se interpreta, pues, por lo expresado por el testador, pero bajo la presunción que existe una correlación entre su voluntad interna y la que ha exteriorizad o y teniéndose en consideración que la autonomía de su voluntad está limitada por las normas que preceptivamente regulan sus disposiciones, especialmente las patrimoniales, por lo que, por ejemplo, la exclusión de un heredero forzoso no puedetener otra vía queno sea la dela desheredación por el propio testador y por causal prevista en la ley.

El art. 1680, al disponer que la interpretación debe hacerse de acuerdo con lo expresado, disponetambién la aplicación del principio de la buena feque, en el caso del acto testamentario es inaplicable pues, tratándose de una buena fe en sentido objetivo, atendiendo al carácter unilateral, aunque recepticio y 
mortis causa del testamento, la voluntad del testador no es producto de una tratativa ni el testador queda vinculado con los beneficiarios de sus disposiciones.

La interpretación sistemática dispuesta por el art. 169o es perfectamente aplicable al acto testamentario, que debe ser interpretado considerando la interdependencia desus cláusulas y aclarar, de estemodo, las dudas quepueda generar una expresión defectuosa.

Por último, es necesario considerar la aplicabilidad de la norma del art. 170으 y ponerse en la hipótesis de que el testador haya utilizado expresiones ambiguas. En tal caso, el hermeneuta no tendrá otra al ternativa queinterpretar tales expresiones adecuándolas a la naturaleza del acto testamentario y a su finalidad.

1 Vide, Ferrero, A. Derecho deSucesiones, Lohmann Luca deTena, Guillermo. Derecho deSucesionesy Echecopar García, L. Derecho deSucesiones.

2 Vide, del autor, El Acto Jurídico, Págs. 347 y sgtes.

3 Derecho deSucesiones, T. II, Págs. 205y sgtes.

4 Ibidem, Págs. 221 y 222.

5 El A cto Jurídico, Pág. 347 y sgtes. 